
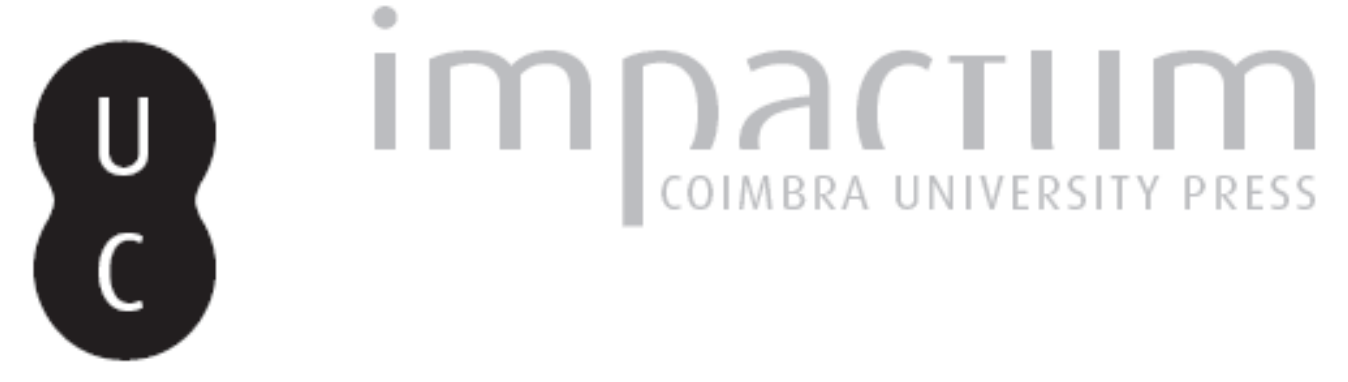

\title{
Uma perspectiva antropológica da obesidade
}

\section{Autor(es): Padez, Cristina}

Publicado por: CIAS - Centro de Investigação em Antropologia e Saúde

URL persistente:

URI:http://hdl.handle.net/10316.2/41245

DOI:

DOI:http://dx.doi.org/10.14195/2182-7982_17_9

Accessed : $\quad$ 26-Apr-2023 10:38:38

A navegação consulta e descarregamento dos títulos inseridos nas Bibliotecas Digitais UC Digitalis, UC Pombalina e UC Impactum, pressupõem a aceitação plena e sem reservas dos Termos e Condições de Uso destas Bibliotecas Digitais, disponíveis em https://digitalis.uc.pt/pt-pt/termos.

Conforme exposto nos referidos Termos e Condições de Uso, o descarregamento de títulos de acesso restrito requer uma licença válida de autorização devendo o utilizador aceder ao(s) documento(s) a partir de um endereço de IP da instituição detentora da supramencionada licença.

Ao utilizador é apenas permitido o descarregamento para uso pessoal, pelo que o emprego do(s) título(s) descarregado(s) para outro fim, designadamente comercial, carece de autorização do respetivo autor ou editor da obra.

Na medida em que todas as obras da UC Digitalis se encontram protegidas pelo Código do Direito de Autor e Direitos Conexos e demais legislação aplicável, toda a cópia, parcial ou total, deste documento, nos casos em que é legalmente admitida, deverá conter ou fazer-se acompanhar por este aviso.

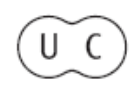




\section{Antropologia Portuguesa}

$16-17 \cdot 1999-2000$

Departamento de Antropologia | Universidade de Coimbra 


\title{
Uma perspectiva antropológica da obesidade
}

\author{
Cristina Padez \\ Departamento de Antropologia \\ Universidade de Coimbra \\ 3000-056 Coimbra, Portugal \\ cpadez@ci.uc.pt
}

\section{Resumo}

Uma abordagem antropológica da obesidade humana envolve a reflexão em torno das dimensões evolutiva e cultural. Durante 95 a 99\% da história da humanidade as populações viveram um padrão de subsistência de caçadores-recolectores em que eram frequentes os períodos de escassez de alimentos. Alguns autores colocam a hipótese de terem sido seleccionados os fenótipos com maior capacidade de armazenar energia na forma de gordura. Contudo, as profundas alterações ambientais recentemente verificadas, sobretudo as associadas à alimentaçĩo e à actividade física, fazem com que os nossos velhos genes sejam desadequados para o actual tipo de alimentação e para os níveis elevados de sedentarismo. Esta será a principal causa para a actual epidemia de prevalência de obesidade nos países industrializados.

\section{Palavras-chave}

Obesidade, evoluçāo, caçadores-recolectores, alimentação

\section{Abstract}

An anthropological perspective on obesity should considers both its evolutionary background and cross-cultural variation. For 95 to $99 \%$ of our history, humankind lived exclusively as hunters and gathers with periodic food shortages. Such shortages, particularly disadvantageous to women in their reproductive years, favored individuals who, for biological and cultural reasons, stored fat. However, the great changes that occurred in our environment especially in our diet and physical activity have created not a genetic, but a new environmental problem. It is argued that the main factors responsible for obesity in industrialized nations are environmental.

\section{Key words}

Obesity, evolution, hunters and gathers, diet 


\section{Introdução}

A abordagem antropológica da obesidade humana envolve uma dimensão evolutiva e cultural: procura compreender como é que a predisposição para a obesidade, tão evidente nas sociedades actuais, pode ter sido determinante durante a nossa longa história evolutiva enquanto caçadoresrecolectores, assim como tenta explicar a variação na prevalência de obesidade em diferentes sociedades, classes sociais e grupos étnicos (Brown e Konner, 1987).

É importante analisar a obesidade numa perspectiva evolutiva devido à longa história da humanidade. Os primeiros representantes do género Homo surgiram há cerca de 2 milhões de anos e os primeiros humanos anatomicamente modernos (Homo sapiens) datam de há cerca de 100000 anos (Klein, 1999). Assim, para a maior parte da nossa história, o padrão cultural exclusivo foi o de caçadores-recolectores. Estas sociedades tiveram uma actividade de subsistência segundo a qual um terço da alimentação era de origem animal, proveniente da caça, e dois terços de origem vegetal compreendendo produtos como frutas, raizes, tubérculos, folhas, entre outros (Boas e Almquist, 1997).

Nesta análise antropológica da obesidade torna-se importante perceber o nosso percurso evolutivo porque, de facto, para a maior parte da história da humanidade, a obesidade nunca foi um problema de saúde frequente, nem um cenário possível para a maioria das pessoas. Isto porque, apesar da qualidade adequada em termos de dieta, a maioria das sociedades de caçadores-recolectores foram sujeitas a períodos de escassez de alimentos com muita frequência, o que terá constituído um poderoso agente da selecçāo natural na evolução biocultural humana.

\section{Evolução e obesidade: dieta, escassez de alimentos e adaptação}

Ambos, genes e estilo de vida, estão envolvidos na etiologia da obesidade, embora a importância relativa de cada um dos factores, e a maneira pela qual interactuam, não estejam inteiramente compreendidas. Sugere-se que ambos, predisposição genética e cultural para a obesidade, 
possam ser produtos das mesmas pressões evolutivas, envolvendo dois processos relacionados: primeiro, as características que causam adiposidade foram selecionadas porque elas aumentavam as hipóteses de sobrevivência, em presença de escassez de alimentos, particularmente para mulheres grávidas e em amamentação; segundo, a adiposidade pode ter sido directamente seleccionada porque é um símbolo cultural de prestígio social e um índice de saúde em geral, nestas populações (Stunkard et al., 1986).

\section{Evolução cultural desde a colecta até à produção de alimentos}

Avaliando o trajecto da humanidade estima-se entre 95 a $99 \%$ o período vivido em economia de subsistência como caçadores-recolectores. Investigações nestas sociedades actuais revelam algumas semelhanças culturais e biológicas apesar da variabilidade do seu contexto ecológico: vivem em grupos pequenos, socialmente flexíveis, seminómadas, com taxas de crescimento lentas devido a um prolongado período de amamentação e a uma elevada taxa de mortalidade infantil. Praticam dietas de elevada qualidade e dispendem proporcionalmente pouco tempo para a recolecção de alimentos. São geralmente saudáveis e mais bem nutridos do que a maioria dos habitantes dos actuais países em vias de desenvolvimento com populações vivendo na dependência da agricultura.

Há aproximadamente 10000 anos alguns grupos humanos mudaram a sua economia de colecta de alimentos para uma economia de produção. Segund Tudge (1998) esta mudança não foi repentina, como a generalidade dos autores considera, mas ocorreu gradualmente. De acordo com este autor, é possível que os caçadores-recolectores já tivessem ocasionalmente praticado alguma horticultura. Esta mudança requereu a domesticação de plantas e animais, num processo evolutivo em que os humanos actuaram como agentes de selecção. Esta transformação económica gradual, culminou numa actividade agrícola intensa, conhecida como a Revolução Neolítica, e pode ser considerada como o evento mais importante na história humana porque permitiu o crescimento populacional e a evolução de sociedades ditas complexas, o incremento de estados e de civilizações. A nova economia, baseada na agricultura, foi um processo que as pessoas foram, efectivamente, forçadas a adoptar por causa das pressões ecológicas devidas ao crescimento populacional e à escassez de alimentos (Wenke, 1980). Apesar das limitações no estudo de crescimen- 
to e tamanho das populações do passado, alguns trabalhos evidenciam uma diminuição na velocidade de crescimento e no tamanho adulto final, à medida que a agricultura se intensificou, associados a um stress nutricional (Ulijaszek, Johnston e Preece, 1998).

A obesidade não é simplesmente uma doença de civilização, é comum somente em certos tipos de sociedades industrializadas - aquelas que dispōem de um nível absoluto de afluência em que até os pobres têm acesso a alimentos suficientes para se tornarem gordos. Trowell (1975) tem sugerido que somente há cerca de 200 anos a obesidade se tornou comum na Europa, primeiro em élites e depois nos restantes grupos.

\section{A proporcionalidade das dietas pré-industriais}

A qualidade da dieta dos caçadores-recolectores, e por analogia a dos nossos antepassados pré-históricos, tem sido objecto de considerável interesse. A análise dos componentes nutricionais da dieta paleolítica sugere que era rica em proteínas, fibras e hidratos de carbono vegetais, com baixo teor de açúcares e de gorduras saturadas (Eaton e Konner, 1985). Existem notáveis semelhanças entre esta dieta, reconstruída a partir de registos fósseis, e as recomendações actuais para as nossas necessidades nutricionais elaboradas pelos comités de nutrição. A dieta paleolítica poderia ser considerada um modelo de dieta preventiva, mais rigorosa e, provavelmente, mais saudável até do que a actualmente recomendada. Mas estes factos reflectem limitações na disponibilidade e na escolha de alimentos em vez de uma sabedoria sobre uma dieta nutricionalmente adequada. Os inúmeros estudos sobre sociedades em mudança cultural têm repetidamente mostrado que quando em populações tradicionais, com dietas saudáveis, surge a oportunidade de mudança há alterações para uma dieta menos saudável, excepto em termos de abundância, a exemplo das dietas ocidentais (Bindon, 1995).

\section{A ubiquidade de escassez de alimentos}

A escassez de alimentos tem sido tão comum na pré-história e história humanas que pode ser considerada como um facto virtualmente inevitável da vida no passado. Whiting (1958) efectuou um estudo comparativo entre várias culturas tendo analisado a alimentação de 115 sociedades préindustriais. Em 28,7\% destas sociedades, os períodos de escassez sāo raros ocorrendo todos com intervalos de 10 a 15 anos, enquanto em $24,3 \%$ 
eles tiveram lugar todos os 2-3 anos. Períodos de escassez ocorreram, anualmente, em $47 \%$ das sociedades. Metade destes acontecimentos foram provocados por condiçōes climáticas tais como a falta de pluviosidade.

A análise da dimensão relativa destes periodos de escassez de alimentos mostrou que em 113 populações estudadas, $29,3 \%$ sofreram privações alimentares caracterizadas por periodos de fome generalizada. Escassez média, período em que os alimentos armazenados foram utilizados e em que as pessoas chegaram a perder peso, verificou-se em $34,4 \%$ das sociedades. Finalmente, $36,3 \%$ tiveram períodos de escassez mínima, com redução do número habitual de refeições, que se reflectiram em apenas alguma perda de peso, mas sem grande severidade (Whiting, 1958).

\section{Adaptações biológicas à escassez de alimentos}

Os períodos de escassez de alimentos sugerem uma hipótese para a evolução da obesidade. Uma vez que os períodos de escassez foram ubíquos para os humanos em condições naturais, a selecção natural favoreceu os indivíduos que conseguiam efectivamente armazenar calorias em tempos de abundância. Para $3 / 4$ das sociedades essa gordura armazenada seria gasta todos os 2-3 anos.

Os dados médicos de vítimas da fome mostram que, para além da morte por inanição, a malnutrição causada pela escassez de alimentos tem um efeito de sinergia na mortalidade por doenças infecciosas, assim como uma diminuição do peso ao nascimento e nas taxas de crescimento das crianças (Tanner, 1990). As mulheres com maiores reservas de energia em gordura têm vantagem selectiva sobre as mulheres magras no que concerne ao combate ao stress da escassez de alimentos, não apenas para elas próprias, mas também para os seus fetos e para as crianças que amamentam. Ou seja, os humanos evoluíram no sentido de armazenar a energia de alimentos para os inevitáveis períodos de escassez através da síntese e armazenamento de gordura.

Neste contexto evolutivo, a normal distribuição da variação do metabolismo humano teria dado origem a muitos indivíduos com uma predisposição para se tornarem obesos embora, de facto, com toda a probabilidade, nunca tenham tido oportunidade para isso. Além disso, neste contexto deveria ter havido pouca ou nenhuma selecção sobre esta tendência. 
A selecção nunca teria providenciado para a eventualidade de uma contínua abundância de alimentos simplesmente porque ela nunca existiu (Brown e Konner, 1987).

\section{Prevalência de obesidade nos países industrializados}

A obesidade, definida como um índice de massa corporal (IMC) $\geq 30$, é um problema grave de saúde nos países industrializados (WHO, 1998).

Constatou-se, recentemente, um aumento alarmante na prevalência de obesidade no "Mundo Ocidental" (Kuczmarski et al., 1994). Um terço da população americana é, presentemente, considerada obesa, e a prevalência de obesidade nas crianças situa-se numa escalada inquietante, permitindo prever um futuro quase assustador em termos de saúde pública (Troiano et al., 1995). Baseados na prevalência de obesidade nos últimos 30 anos, Foreyt e Goodrick (1995) prevêem que a totalidade da população americana será obesa no século XXIII.

A obesidade tem custos significativos para a sociedade uma vez que aumenta o risco para as doenças e a mortalidade em geral, agrava os custos dos cuidados de saúde associados a um incremento na frequência de morbilidade e condiçōes psiquiátricas, reduz o status social e as oportunidades de emprego (WHO,1998).

Apesar dos valores mais elevados terem lugar na população americana, com taxas de prevalência de obesidade ajustadas à idade para homens e mulheres, de 19,5 e $25 \%$, respectivamente (WHO, 1998), outros países apresentam uma evolução preocupante. Em Inglaterra, entre 1980 e 1991, a prevalência de obesidade aumentou significativamente em ambos os sexos, passando de 8 para $16,5 \%$ nas mulheres e de 6 para $15 \%$ nos homens (Prentice e Jeeb, 1995).

Portugal não é excepção e apesar dos estudos nesta área serem escassos parece ter havido um aumento considerável nos últimos anos. Em jovens adultos do sexo masculino, com idades compreendidas entre os 1925 anos, entre 1985 e 1998 a percentagem de indivíduos com excesso de peso passou de $10 \%$ para $13,5 \%$ e a obesidade passou de $0,9 \%$ para $2,9 \%$, isto é, triplicou em 13 anos (Padez, 2000). Estes valores apesar de semelhantes aos encontrados em alguns países europeus (Laurier et al., 1992) não são ainda preocupantes. Contudo, a velocidade do aumento em pes- 
soas tão jovens pode sugerir o aparecimento de graves problemas de saúde, num futuro muito próximo. Vários autores têm salientado a importância da obesidade em jovens adultos como um factor de risco para diferentes tipos de doenças em idades mais tardias (Dietz, 1999; Seidell et al., 1999).

\section{Qual a origem desta epidemia?}

A obesidade não é uma doença unitária e as suas causas são multifactoriais incluindo influências poligénicas, metabólicas, psico-sociais e ambientais (Poston II e Foreyt, 1999).

Embora investigações recentes tenham enfatizado a influência genética na etiologia da obesidade, na forma de uma maior susceptibilidade e nas interações genes-ambiente, a maioria dos autores aceita que as influências ambientais superam largamente as genéticas (Bouchard, 1991; Bouchard, 1994; Weinsier et al., 1998).

Uma vez que é improvável que o pool genético tenha mudado substancialmente durante o século passado, outros factores, que não apenas os genéticos, devem ter influenciado este aumento. Alguns autores (Eaton et al., 1988; Eaton, 1988) sugerem que o pool genético não mudou substancialmente nos últimos 35000 anos mas que, durante este mesmo período de tempo, os seres humanos modificaram radicalmente o meio ambiente que os rodeia, particularmente no último século.

Estudos recentes sugerem que a obesidade resulta de uma má combinação, um quase conflito, entre o nosso moderno estilo de vida e o estilo de vida no qual os humanos, e os nossos genes, evoluíram (WHO, 1998). Embora tenham sido feitos avanços significativos e quase espectaculares na redução das taxas de mortalidade relacionadas com as doenças infecciosas, se tenha melhorado o diagnóstico e tratamento de muitas doenças com o consequente aumento da nossa longevidade, o nosso quadro de mortalidade e morbilidade para as doenças crónicas e degenerativas, as quais estão fortemente associadas ao estilo de vida dos países industrializados, também mudou (Popkin, 1998). O consumo de gorduras no paleolítico estima-se em cerca de $10-20 \%$ de calorias, quando actualmente, na generalidade dos países industrializados, chega a atingir 32\% (Eaton, 1992; Lenfant e Ernst, 1994). Investigações em populações humanas que continuam a ter um modo de subsistência de caçadores-recolectores, assim como registos fósseis, sugerem que os humanos 
eram significativamente mais activos, e as suas dietas energeticamente menos densas, mais ricas em fibras e com menor percentagem de gorduras e menor valor calórico em geral do que as adoptadas pelas sociedades ocidentais actuais (Burkitt e Eaton, 1989). Paradoxalmente, parece que os genes que ajudaram os humanos a sobreviver num mundo caracterizado pela necessidade de uma elevada actividade física e com períodos regulares de escassez de alimentos são agora nefastos num ambiente em que a quantidade e a disponibilidade de alimentos é ampla e o gasto energético para os adquirir é mínimo. Ou seja, é o nosso novo ambiente e não os nossos velhos genes que são problemáticos (Brown e Bentley-Condit, 1998).

\section{Novo ambiente:}

\section{dieta, actividade física e nível sócio-económico}

O ambiente da generalidade dos países industrializados promove padrões de vida e de alimentação pouco saudáveis sendo caracterizado por um ilimitado acesso a alimentos muito saborosos e altamente calóricos (Battle e Brownell, 1996; Hill e Peters, 1998). Ao mesmo tempo, não é necessário gastar muita energia no dia-a-dia porque todos os serviços estão altamente mecanizados: há carros, elevadores, passadeiras rolantes, controlos remotos de televisão e de portas de garagem, enfim, um indeterminado número de facilidades quotidianas. Este ambiente é completamente oposto ao que moldou a evolução humana (Brown e Bentley-Condit, 1998; Eaton, 1988; Eaton et al., 1988).

Existem amplas evidências da importância do meio ambiente na etiologia da obesidade. Muitos trabalhos realizados têm demonstrado que os indivíduos de sociedades pré-industriais que adoptaram estilos de vida ocidentais ganharam peso, parcialmente em resultado do aumento do consumo em calorias de origem animal, proteínas e açúcar, e da dimuição do consumo de vegetais, frutas e hidratos de carbono complexos. Por exemplo, a "ocidentalização cultural" do Japão, entre outros aspectos fez duplicar os valores da obesidade infantil nos últimos 30 anos, à medida que o consumo de gorduras atingiu também valores próximos dos verificados nos Estados Unidos da América (Murata e Hibi, 1992).

A generalidade dos habitantes dos países industrializados comem demasiado e alimentos muito calóricos. Dados referentes aos Estados 
Unidos da América revelam um aumento de cerca de 500 calorias por pessoa/dia entre 1930 e 1990 . Alguns autores referem que, na última década, houve aumentos de $200 \mathrm{Kcal} / \mathrm{dia}$ (Gerrior e Zizza, 1994). Nos estudos sobre países em vias de modernizaçāo, as comparaçōes rural-urbano fornecem informações extremamente importantes acerca do impacto da dieta ocidental. Vários trabalhos têm mostrado que estas nações apresentam aumentos na obesidade e no consumo calórico, característicos dos países ocidentais, porque a urbanização promove um mercado com a distribuição de novos produtos alimentares e uma grande penetração de actividades de mercado (Popkin, 1998).

O consumo de alimentos energeticamente mais densos, sobretudo do chamado fast-food, aumentou na maioria dos países industrializados porque, entre outras razões, devido à sua actividade profissional a generalidade das pessoas toma as refeições fora de casa, constituindo este factor um incentivo para o desenvolvimento desta indústria alimentar. A generalidade das sociedades também aumentou a quantidade de alimentos por refeição. São frequentes os super size de hamburgers, pipocas, bebidas, entre muitos outros produtos (Nestle et al., 1998). Portugal não é excepçāo nestas alterações do padrāo alimentar. Entre 1963 e 1997 teve lugar um aumento de 906 calorias/dia. Por outro lado o consumo de açúcares passou de 209 para 350 calorias e o de gorduras de 99.7 para 135,3 calorias por dia (Barreto, 1996; 2000).

O estilo de vida das sociedades actuais é, também, caracterizado por uma quase ausência de actividade física. Os dados recentes referem que menos de $10 \%$ da população americana está envolvida em actividade física regular e vigorosa (USDHHS, 1996). A prevalência de pouca ou nenhuma actividade física - isto é, o considerado estilo de vida sedentário é de $54 \%$ para a população em geral e de cerca de $70 \%$ para afro-americanos e hispânicos. Estes últimos valores são particularmente alarmantes porque nestas minorias as mulheres sofrem das taxas de obesidade mais elevadas nos Estados Unidos da América (Crespo et al., 1996). O número de horas a ver televisão parece ter sido um contributo importante para esta inactividade, contribuindo também para o elevado sedentarismo das crianças (Gortmaker et al., 1990).

Um trabalho recentemente efectuado em Portugal revela que $60.2 \%$ dos portugueses não pratica qualquer tipo de actividade física (Afonso, 1999). 
Esta ausência de actividade nas sociedades industrializadas é particularmente assustadora quando consideramos a importância da actividade física na evolução humana (Eaton, 1988; Eaton et al., 1988). Isto, porque as sociedades de caçadores-recolectores tinham que ser activas para procurar alimentos para sobreviver. Hoje, nas sociedades industrializadas, ninguém precisa de ser fisicamente activo para procurar alimentos. Basta ir de carro ao supermercado para se abastecer de produtos saborosos e calóricos (Ulijaszek, 1999).

$O$ excesso de calorias e a inactividade são as principais características de um "ambiente pouco saudável". O nível socioeconómico também contribui para a prevalência da obesidade. Existe uma clara associação entre o statıs socioeconómico e o peso corporal, embora esta associação seja diferente em países industrializados ou em países em vias de desenvolvimento.

Nos paises em vias de desenvolvimento há uma tendência para uma associação positiva entre o status socioeconómico e a obesidade nas mulheres, homens e crianças (WHO, 1998; Brown e Bentley-Condit, 1998; Sobal e Stunkard, 1989). Indivíduos com baixo status socioeconómico têm maior probabilidade de estar envolvidos em profissões que requerem elevada actividade física, enquanto que pessoas com maiores recursos têm, provavelmente, maior acesso a uma melhor alimentação e a profissōes que requerem menor dispêndio de energia. Além disso, ser gordo ou ter excesso de peso, num país em vias de desenvolvimento, é muitas vezes visto positivamente, isto é, torna-se um sinal exterior de sucesso e de prestígio social.

Contrariamente, nas nações mais abastadas e heterogéneas, como os Estados Unidos da América, e mesmo na Europa, a relação entre o status socioeconómico e a obesidade tende a ser forte, mas em associação inversa particularmente nas mulheres, embora menos consistente nos homens e crianças (Brown e Bentley-Condit, 1998; Sobal e Stunkard, 1989). Esta relação inversa é esperada uma vez que a falta de alimentos nos países industrializados é rara, e os custos associados a ter-se um corpo "bem proporcionado ou elegante" são caros e podem ser dispendiosos (frequentar um ginásio, adquirir alimentos seleccionados num bom restaurante ou comprar bons alimentos para cozinhar). Pessoas com menores recursos em países desenvolvidos tendem a comer alimentos menos nutritivos, mais densos energeticamente, menor quantidade de fruta, de vegetais e mais alimentos pré-confeccionados (WHO, 1998; Brown e Bentley-Condit, 1998; Shi, 1998). 
Esta relação também se verifica na população portuguesa. Numa amostra de 2401 rapazes e 2913 raparigas, estudantes da Universidade de Coimbra, a relação entre a prevalência de obesidade e o grau de instrução dos pais mostrou que, à medida que aumenta o grau de instrução dos pais, diminui a prevalência de obesidade em ambos os sexos. A prevalência de obesidade encontrada em rapazes e raparigas foi de $40,9 \%$ e $36,8 \%$, respectivamente, no caso de filhos de pais com instrução primária mas apenas de $18,2 \%$ e $26,3 \%$ quando os progenitores tinham nível de instrução universitário (Padez, 2000).

\section{Variações culturais no tipo de corpo ideal}

Para além da associação básica entre gordura e saúde, os padrões culturais de beleza foram provavelmente um factor importante na seleção sexual para fenótipos que predispõem para a obesidade. Um exemplo clássico são as "cabanas de reclusāo" para as adolescentes entre os Annang da Nigéria (Brink, 1995). A rapariga passa até dois anos em reclusão antes de casar, e no final deste rito de passagem é considerada dotada de símbolos femininos e de um aspecto apropriado para o casamento: um arranjo de cabelo sofisticado e uma forma corporal bonita, isto é, gorda. Esta gordura constituiu o primeiro critério de beleza definido pelas elites desta sociedade, aquelas que dispunham de recursos económicos para participar neste ritual.

Mas, até que ponto é comum esta conexão cultural entre beleza e gordura? São escassos os trabalhos sobre definiçōes culturais de beleza ou o tipo ideal de corpo entre as várias sociedades a nível mundial. A ausência de estudos sobre este tema reflecte, em parte, a dificuldade sentida por etnógrafos e historiadores para descreverem adequadamente este elemento cultural. Num trabalho de comparação entre 325 culturas, que não abrangem os Estados Unidos e a Europa, somente 58 dispõem de dados adequados para estimar algumas características do tipo ideal de corpo feminino. Estes dados referem que os padrões culturais de beleza parecem basear-se nas características do grupo socioeconómico dominante da sociedade não se referindo a extremos físicos. Nenhuma sociedade estudada elege como tipo ideal a obesidade extrema. Por outro lado, o desejo de gordura é encontrado em $81 \%$ destas sociedades (Brown e Konner, 1987). 
A obesidade pode também ser um símbolo de maternidade. Em sociedades tradicionais onde a mulher adquiria o seu próprio estatuto através da maternidade, esta associação simbólica aumenta a aceitação cultural da obesidade.

Embora haja uma grande variaçāo cultural quanto aos padrōes de beleza, esta diversidade oscila entre certos limites. O actual ideal americano de magreza ocorre num local onde é fácil tornar-se gordo e a preferência pela gordura ocorre em locais em que é fácil permanecer magro. Ambos os padrões requerem um investimento individual de recursos económicos. Além disso, cada um destes contextos envolve um certo significado de "saúde". Em sociedades pobres os mais abastados pretendem impressionar pela sua gordura. Nas sociedades ricas, mesmo os mais pobres podem-se tornar gordos; então, o rico tem que impressionar permanecendo magro, como que a dizer: "Nós temos tão poucas dúvidas sobre donde virá a nossa próxima refeição, que não precisamos de armazenar uma grama de gordura como energia" (Brown e Konner, 1987).

\section{Bibliografia}

Afonso, C. 1999. Sańde, actividade fisica e peso corporal: contributo para o seu conhecimento numa amostra da populaçĩo adulta Portuguesa. Tese de Mestrado. Porto, Universidade do Porto.

Barreto, A.1996. A Situaçāo Social em Portugal, 1960-1995. Lisboa, Instituto de Ciências Sociais, Universidade de Lisboa.

Barreto, A. 2000. A Situaçāo Social em Portugal, 1960-1999. Lisboa, Instituto de Ciências Sociais, Universidade de Lisboa.

Battle, E. K.; Brownell, K. D.1996. Confronting the rising tide of eating disorders and obesity: Treatment vs prevention and policy. Addictive Behaviour, 21:755-765.

Bindon, J. R.1995. Polynesian responses to modernization: overweight and obesity in the South Pacific. In: Garine, I.; Pollock, N.J. (ed.). Social Aspects of Obesity. Luxembourg, Gordon and Breach Publishers: 227-251.

Boas, N. T.; Almquist, A. J. 1997. Biological Anthropology. New Jersey, Prentice Hall.

Bouchard, C. 1991. Current understanding of the etilogy of obesity: genetic and nongenetic factors. American Joumal Clinical Nutrition, 53:1561S-1565S. 
Bouchard, C. 1994. Genetics of obesity: overview and research direction. In: Bouchard, C. B. (ed.). The Genetics of Obesity. Boca Raton, FL CRC Press: 223-233.

Brink, P. J. 1995. Fertility and fat: The Annang Fattening Room. In: Garine, I.; Pollock, N. J. (ed.). Social Aspects of Obesity. Luxembourg, Gordon and Breach Publishers: 71-85.

Brown, P.J.; Bentley-Condit, V. K. 1998. Culture, evolution, and obesity. In: Bray, G. A., Bouchard, C.; James, W. P. T. (ed.). Handbook of obesity. New York, Marcel Dekker:143-155.

Brown, P.J.; Konner, M.1987. An anthropological perspective on obesity. Amnals New York Acadeny Sciences, 499: 29-46.

Burkitt, D. P.; Eaton, S. B.1989. Putting the wrong fuel in the tank. Nutrition, 5:189-191.

Crespo, C. J.; Keteyian, S. J.; Heath, G. W.; Sempos, C. T. 1996. Leisure-time physical activity among US adults. Results from the Third National Health and Nutrition Examination Survey. Archives Internal Medicine, 156:93-98.

Dietz, W. 1999. How to tackle the problem? The role of education in the prevention of obesity. International Journal Obesity, 23:S7-S9.

Eaton, S. B. 1988. The Paleolithic prescription. New York, Harper \& Row.

Eaton, S. B. 1992. Humans, lipids and evolution. Lipids, 27: 814-820.

Eaton, S. B.; Konner, M. 1985. Paleolithic nutrition: a consideration of its nature and current implications. New' England Journal Medicine, 312: 283-289.

Eaton, S. B.; Konner, M.; Shostak, M. 1988. Stone agers in the fast lane: chronic degenerative diseases in evolutionary perspective. American Joumal of Medicine, 84:739-749.

Foreyt, J. P.; Goodrick, G. K. 1995. The ultimate triumph of obesity. Lancet, 346:134-135.

Gerrior, S. A.; Zizza, C. 1994. Nutrient content of the U.S. food supply 19091990. Home economics Research Report No. 52. Washington, DC, United States Department of Agriculture.

Gortmaker, S. L.; Dietz, W. H.; Cheung, L. W. Y. 1990. Inactivity, diet, and the fattening of America. Joumal American Dietetic Association, 90:1247-1252.

Hill, J. O.; Peters, J. C. 1998. Environmental contributions to the obesity epidemic. Science, 280:1371-1374.

Klein, R. G. 1999. The Human Career: Iuman biological and cultural origins. 2nd ed. Chicago, University of Chicago Press.

Kuczmarski, R. J.; Flegal, K. M.; Campbell, S. M.; Johnson, C. L. 1994. 
Increasing prevalence of overweight among US adults. Joumal of American Medical Association, 272:205-211.

Laurier, D.; Guiguet, M.; Chau, N. P.; Wells, J. A.; Valleron, A-J. 1992. Prevalence of obesity: a comparative survey in France, the United Kingdom and the United States. International Journal Obesity, 16:565-572.

Lenfant, C.; Enst, N.1994. Daily dietary fat and total food-energy intakes - Third National Health and Nutrition Examination Survey, Phase 1, 1988-1991. M.M.W.R., 43:116-125.

Murata, M.; Hibi, I. 1992. Nutrition and the secular trend of growth. Hormone Research, 38:89-96.

Nestle, M.; Wing, R.; Birch, L. 1998. Behavioral and social influences on food choice. Nutrition Review, 56:S50-S74.

Padez, C. 2000. Overweight and obesity in Portuguese young men: prevalence and trends. Acta Medica Aurológica, 32:59.

Popkin, B. M. 1998. The nutrition transition and its health implications in lower-income countries. Public Health Nutrition, 1:5-21.

Poston II, W. S.; Foreyt, J. P. 1999. Obesity is an environmental issue. Atherosclerosis, 146:201-209.

Prentice, A. M.; Jebb, S. A. 1995. Obesity in Britain: gluttony or sloth? British Medical Journal, 311: 437-439.

Seidell, J. S.; Visscher, T. L. S.; Hoogeveen, R. T. 1999. Overweight and obesity in the mortality rate data: current evidence and research issues. Medicine \& Science Sports \& Exercise, 31: S597-S601.

Shi, L. 1998. Sociodemographic characteristics and individual health behaviors. Social Science \& Medicine, 91:933-941.

Sobal, J.; Stunkard, A. J. 1989. Socioeconomic status and obesity: a review of the literature. Psychological Bulletin, 105:260-275.

Stunkard, A. J.; Sorenson, T. I. A.; Hanis, C.; Teasdale, T. W.; Chakaborty, R.; Schull, W. J.; Schulsinger, F. 1986. An adoption study of obesity. New England Journal Medicine, 314:193-198.

Tanner, J. M. 1990. Foetus into Man. Physical Growth from Conception to Maturity. Cambridge, Harvard University Press.

Troiano, R. P.; Flegal, K. M.; Kuczmarski; R. J.; Campbell, S. M.; Johnson, C. L. 1995. Overweight prevalence and trends for children and adolescents. Archives Pediatrics Adolescent Medicine, 149:1085-1091.

Trowell, H. 1975. Obesity in the western world. Plant Foods for Man, 1:157165. 
Tudge, C. 1998. Neanderthals, Bandits, and Farmers. London, Weidenfeld \& Nicolson.

Ulijaszek, S. J. 1999. Physical activity, lifestyle and health of urban populations. In: Schell, L. M.; Ulijaszek, S. J. (ed.). Urbanism, Health and Human Biology in Industrialized Conntries. Cambridge, Cambridge University Press: 250-279.

Ulijaszek, S. J.; Johnston, F. E.; Preece, M. A. 1998. The Cambridge Encyclopedia of Human Growth. Cambridge, Cambridge University Press.

USDHHS 1996. Physical activity and health: A report of the Surgeon General. Atlanta, GA, U.S. Department of Health and Human Services, Centers for Disease Control and Prevention, National Center for Chronic Disease Prevention and Health Promotion.

Weinsier, R. L.; Hunter, G. R.; Heine, A. F.; Goran, M. I.; Sell, S. M. 1998. The etiology of obesity: Relative contribution of metabolic factors, diet, and physical activity. American Joumal of Medicine, 105:145-150.

Wenke, R. J. 1980. Patterns in Prehistory. Oxford, Oxford University Press.

Whiting, M. G. 1958. A cross-cultural nutrition survey. $\mathrm{PhD}$ thesis. Cambridge, University of Massachusetts.

WHO 1998. Obesity: Preventing and managing the global epidemic. Report of a WHO consultation on obesity. Geneva, Switzerland; World Health Organization. 